\title{
$\beta$-sitosterol induces G1 arrest and causes depolarization of mitochondrial membrane potential in breast carcinoma MDA-MB-231 cells
}

\author{
Shanthi Sri Vundru', Raosaheb K Kale ${ }^{1,2}$ and Rana P Singh ${ }^{1,2^{*}}$
}

\begin{abstract}
Backgrounds: It is suggested that dietary phytosterols, such as $\beta$-sitosterol (ST), have cancer chemopreventive effects; however, studies are limited to support such claims. Here, we evaluated the efficacy of ST on three different human cancer cell lines including skin epidermoid carcinoma A431 cells, lung epithelial carcinoma A549 cells and breast adenocarcinoma MDA-MB-231.
\end{abstract}

Methods: Cell growth assay, cell cycle analysis, FACS, JC-1 staining, annexin V staining and immunoblotting were used to study the efficacy of ST on cancer cells.

Results: ST (30-90 $\mu \mathrm{M})$ treatments for $48 \mathrm{~h}$ and $72 \mathrm{~h}$ did not show any significant effect on cell growth and death in A431 cells. Whereas similar ST treatments moderately inhibited the growth of A549 cells by up to 13\% ( $p \leq 0.05$ ) in $48 \mathrm{~h}$ and $14 \%$ ( $p \leq 0.05-0.0001)$ in $72 \mathrm{~h}$. In MDA-MB-231 cells, ST caused a significant dose-dependent cell growth inhibition by $31-63 \%$ ( $p \leq 0.0001)$ in $48 \mathrm{~h}$ and $40-50 \%$ ( $p \leq 0.0001)$ in $72 \mathrm{~h}$. While exploring the molecular changes associated with strong ST efficacy in breast cancer cells, we observed that ST induced cell cycle arrest as well as cell death. ST caused G0/G1 cell cycle arrest which was accompanied by a decrease in CDK4 and cyclin D1, and an increase in p21/Cip1and p27/Kip1 protein levels. Further, cell death effect of ST was associated with induction of apoptosis. ST also caused the depolarization of mitochondrial membrane potential and increased Bax/BCl-2 protein ratio.

Conclusions: These results suggest prominent in vitro anti-proliferative and pro-apoptotic effects of ST in MDA-MB231 cells. This study provides valuable insight into the chemopreventive efficacy and associated molecular alterations of ST in breast cancer cells whereas it had only moderate efficacy on lung cancer cells and did not show any considerable effect on skin cancer cells. These findings would form the basis for further studies to understand the mechanisms and assess the potential utility of ST as a cancer chemopreventive agent against breast cancer.

Keywords: Lung cancer, Skin cancer, Breast cancer, Cell proliferation, Cell death, Cell cycle and apoptosis

\section{Background}

Among many cancers, breast cancer in females and lung cancer in males are the most frequently diagnosed cancers and the leading cause of cancer death for each sex in both economically developed and developing countries [1]. Lung cancer accounted for $13 \%$ of the total cases and $18 \%$ of the deaths due to cancer occurred in 2008 [1]. Skin cancer is the major cutaneous malignancy

\footnotetext{
* Correspondence: ranaps@hotmail.com

'School of Life Sciences, Central University of Gujarat, Gandhinagar, Gujarat, India

${ }^{2}$ Cancer and Radiation Biology Laboratory, School of Life Sciences, Jawaharlal Nehru University, New Delhi, India
}

\section{() Biomed Central}

and about 76,250 people are estimated to be diagnosed for skin cancer in 2013 [2]. Incidence rate for melanoma has been rising from past three decades. Breast cancer is by far the most frequent cancer among women with an estimated $23 \%$ of all cancers and is the most frequent cause of cancer death in women [1].

The use of natural, synthetic or biological agents to prevent, reverse or suppress the growth and progression of cancer is referred as chemoprevention of cancer [3]. It is one of the most promising strategies for cancer control, and is accomplished by various means including chemoprevention by phytochemicals from vegetables, 
fruits, spices, teas, herbs and medicinal plants thus making it as one of the most feasible means of cancer control [4]. Phytochemicals are secondary plant metabolites and have been used for centuries throughout the world in traditional cures and herbal remedies, and as ayurvedic and homeopathic medicines in India. More recently, there has been a considerable interest in secondary plant metabolites because of their potential preventative effects on chronic diseases including cancer.

Many studies have demonstrated that phytochemicals in common fruits and vegetables can have complementary and overlapping mechanisms of action, including antioxidant activity, scavenging free radicals and regulation of gene expression, including oncogenes and tumor suppressor genes, in cell proliferation and cell differentiation; induction of cell-cycle arrest and apoptosis; modulation of enzyme activities in detoxification, oxidation and reduction; stimulation of the immune system; regulation of hormone metabolism; and antibacterial and antiviral effects [5-7]. Phytosterols (PS) are triterpenes that are important structural components of plant membranes. More than 200 different types of phytosterols have been reported in plant species. The richest sources of phytosterols are vegetable oils, nuts, cereal products, fruits and berries [8]. Structural resemblance of PS with cholesterol enables them to displace low-density lipoprotein (LDL) cholesterol in the human intestine [9]. Protective effects of PS against cardiovascular diseases (CVD), colon and breast cancer developments have been widely documented. The most common dietary phytosterols are $\beta$-sitosterol, campesterol and stigmasterol. Among these, the most abundant phytosterol is $\beta$-sitosterol. Studies have shown that $\beta$-sitosterol exhibits anti-inflammatory, angiogenic and immune-modulating properties [10]. $\beta$-sitosterol is reported to activate Fas signaling in breast cancer cells [11], and induce cell cycle arrest and apoptotic cell death in prostate cancer cells $[12,13]$.

Herein, we evaluated the efficacy of $\beta$-sitosterol on three different cancer cell lines including human skin epidermoid carcinoma cell line (A431), human lung epithelial carcinoma cell line (A549) and human breast adenocarcinoma cell line (MDA-MB-231). It was observed that as compared to A431 and A549 cells, $\beta$-sitosterol showed prominent growth inhibitory and pro-apoptotic activity in MDA-MB231 cells. Further, study provides valuable insight into the chemopreventive efficacy and associated molecular alterations of $\beta$-sitosterol in breast cancer cells in culture.

\section{Methods}

\section{Cell lines and reagents}

A431 and A549 cells were from ATCC (Manassas, USA) and MDA-MB-231 cells were from NCCS Pune, India. These cells were cultured in DMEM, RPMI-1640 and L-15, respectively, each with $10 \%$ fetal bovine serum, 100 units $/ \mathrm{ml}$ penicillin and $100 \mu \mathrm{g} / \mathrm{ml}$ streptomycin at $37^{\circ} \mathrm{C}$ in a humidified $95 \%$ air and $5 \% \mathrm{CO}_{2}$ atmosphere. $\beta$-sitosterol (ST) was obtained from Sigma Chemical Co. (St. Louis, MO, USA; Figure 1A). ST was dissolved in DMSO and an equal amount $(0.1 \% \mathrm{v} / \mathrm{v})$ of DMSO was present in all the treatment groups including control. Anti-CDK4, cyclin D1 antibodies were from Santa Cruz Biotechnology (CA, USA); anti-betaactin antibody was from Sigma; and anti-p21/Cip1, p27/Kip1, phospho and total Erk1/2 and Akt, and HRPconjugated secondary antibodies were from Cell Signaling Technology (MA, USA).

\section{Cell growth and death assays}

A431, A549 and MDA-MB-231 cells $\left(1 \times 10^{5}\right)$ were plated in $60 \mathrm{~mm}$ culture dishes, and next day fed with fresh medium and treated with different doses of ST (30, 60 and $90 \mu \mathrm{M})$ in complete medium. After 48 and $72 \mathrm{~h}$ of these treatments, total cells were collected by brief trypsinization, and washed with PBS. Total cell number was determined by counting each sample in duplicate using a hemocytometer under an inverted phase contrast microscope (Carl Zeiss) using trypan blue dye. Dead cells could not exclude the dye and showed blue staining of the cell. Each treatment for each time point was done in triplicates. Experiments were repeated at least twothree times.

\section{Cell cycle analysis}

A431, A549 and MDA-MB-231 cells were grown at similar confluency as in cell growth assay, and treated with desired doses of ST $(0,30,60$ and $90 \mu \mathrm{M})$ in complete medium for 48 and $72 \mathrm{~h}$. At the end of each treatment time, cells were collected after a brief incubation with trypsin-EDTA followed by processing for cell cycle analysis as reported earlier [14]. Briefly, $0.5 \times 10^{5}$ cells were suspended in $0.5 \mathrm{ml}$ of saponin/propidium iodide (PI) solution [0.3\% saponin (w/v), $25 \mu \mathrm{g} / \mathrm{ml}$ PI (w/v), $0.1 \mathrm{mM}$ EDTA and $10 \mu \mathrm{g} / \mathrm{ml}$ RNase (w/v) in PBS], and incubated over night at $4^{\circ} \mathrm{C}$ in dark. Cell cycle distribution was then analyzed by flow cytometry using FACS Aria III flow cytometer (BD Biosciences, San Jose, CA, USA) at Central Instrument Facility, Central University of Gujarat, Gandhinagar.

\section{Annexin $\mathbf{V}$ apoptosis assay}

To quantify ST-induced apoptotic death of MDA-MB231 cells, annexin V/PI staining was performed followed by flow cytometry, as described earlier [15]. Cells were seeded and treated with 0,60 and $90 \mu \mathrm{M}$ of ST for $48 \mathrm{~h}$. Briefly, after treatment, both floating and attached cells were pooled and subjected to annexin V/PI staining using FITC Annexin V Apoptosis Detection Kit 1 from BD Biosciences, USA and following the step-by-step protocol provided by the manufacturer. 

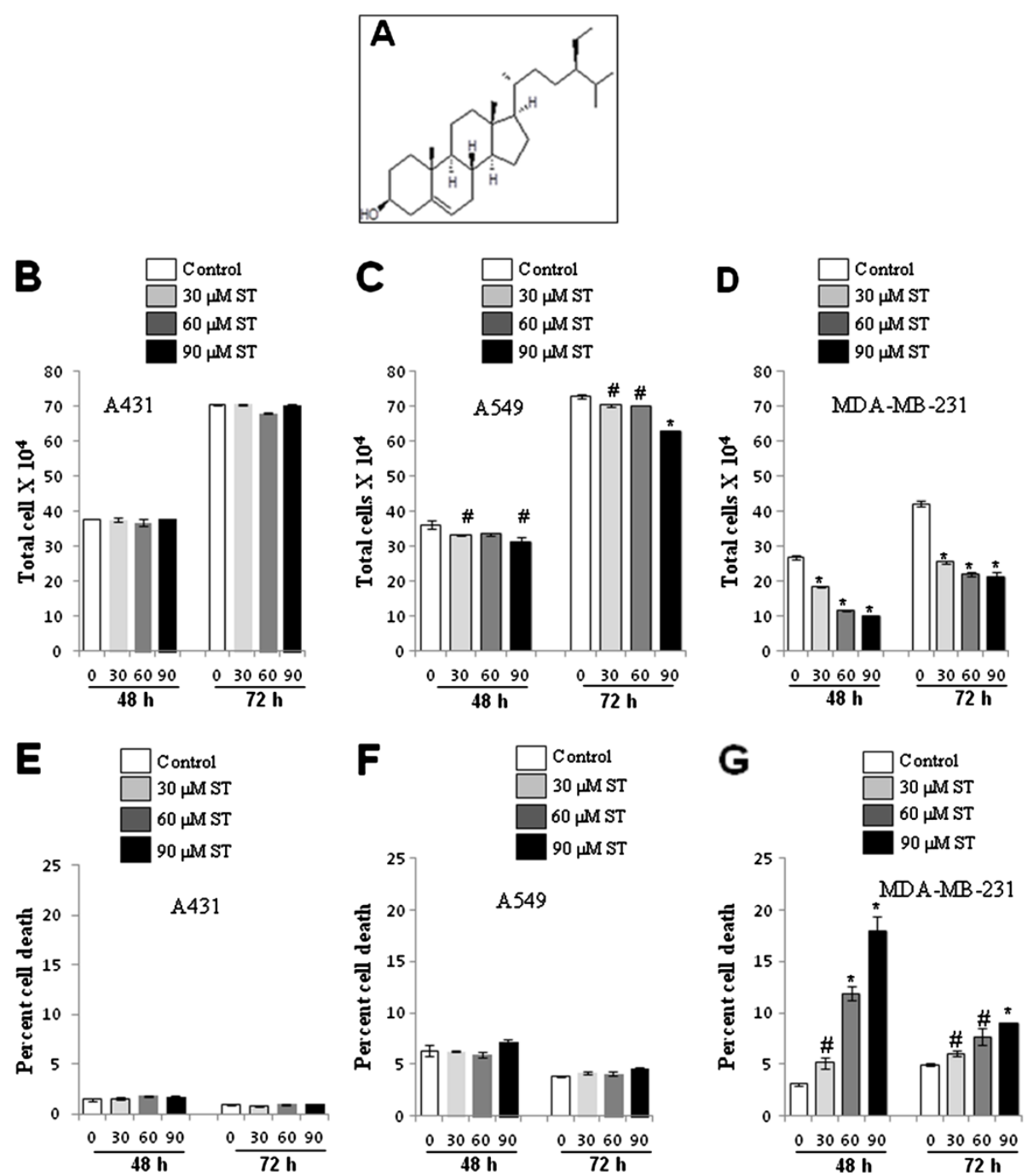

Figure 1 Effect of $\beta$-sitosterol (ST) on growth and cell death in human cancer cells. (A) Chemical structure of $\beta$-sitosterol, Chemical formula:17-(5-Ethyl-6- methylheptan-2-yl)-10,13-dimethyl-2,3,4,7,8,9,11,12,14,15,16,17-dodecahydro-1H cyclopenta[a]phenanthren-3-ol. Cells were plated overnight and treated with either DMSO control or 30,60 and $90 \mu \mathrm{M} \beta$-sitosterol for 48 and $72 \mathrm{~h}$. At the end of treatment, cells were collected and counted with hemocytometer after staining with trypan blue dye using phase contrast inverted microscope for total cell number of (B) A431, (C) A549 and (D) MDA-MB-231; and percent dead cells of (E) A431, (F) A549 and (G) MDA-MB-231. Data shown are mean \pm S.E. of triplicate samples for each treatment. \#, $\mathrm{p}<0.05 ; \$, \mathrm{p}<0.01 ;{ }^{*}, \mathrm{p}<0.001$ compared with the respective controls.

Analysis of mitochondrial transmembrane potential $(\Delta \Psi \mathrm{m})$ To analyse mitochondrial transmembrane potential and determine JC-1 monomer/ JC-1 dimer ratio, MDA-MB231 cells were seeded and treated with 0,60 and $90 \mu \mathrm{M}$ of ST for $24 \mathrm{~h}$. Cells were harvested, volume was adjusted to $1 \mathrm{ml}$ for $2 \times 10^{5}$ cells by adding pre-warmed $\left(37^{\circ} \mathrm{C}\right)$ fresh cell culture medium, $2.5 \mu \mathrm{l} \mathrm{JC}-1$ dye was added from $5 \mathrm{mg} / \mathrm{ml} \mathrm{JC-1}$ dye stock to cell suspension. Then cell suspension was gently mixed until dye got properly dissolved and incubated for $10 \mathrm{~min}$ in dark at $37^{\circ} \mathrm{C}$. Cell suspension was washed with $2 \mathrm{ml} 1 \mathrm{X}$ PBS and centrifuged at $1500 \mathrm{rpm}$ for $5 \mathrm{~min}$, discarded the supernatant and repeated the wash. Cells were resuspended in $0.3 \mathrm{ml}$ 1X PBS. Subsequently, cells were analyzed with
BD FACS Aria III flow cytometer as reported earlier [16]. Data was analyzed as JC-1 monomer/dimer ratio.

\section{Immunoblot analysis}

MDA-MB-231 cells were treated with ST (0, 60, and $90 \mu \mathrm{M})$ for $48 \mathrm{~h}$ and whole cell lysates were prepared as described [17]. Protein estimation was done by Bradford method. Lysates (60-80 $\mu \mathrm{g} /$ sample) were denatured in SDS-PAGE sample buffer and boiled on water bath for 5 min. Samples were loaded onto $12 \%$ denaturing SDSPAGE gels and proteins resolved at constant voltage. Proteins from the gel were transferred onto nitrocellulose membrane using transfer assembly. Membranes were blocked in blocking buffer for $1 \mathrm{~h}$ and incubated 
with specific primary antibodies followed by appropriate HRP-linked secondary antibody and processed for ECL detection. Bands on films were scanned using high resolution scanner [18].

\section{Statistical analysis}

All statistical analyses were carried out with Sigma Stat software version 2.03 (Jandel Scientific, San Jose, CA, USA). Student's $t$-test was used for comparing the control group with treatment groups for statistical significance. $P<0.05$ was considered significant. All the experiments were repeated at least twice with similar results.

\section{Results}

Effect of $\beta$-sitosterol on growth and death of cancer cells Trypan blue is a diazo dye which can not be excluded from the dead cells. This method is also known as a dye exclusion method. This test is used to determine the number of viable cells present in a cell suspension. It is based on the principle that live cells possess intact cell membranes that exclude dyes such as trypan blue, whereas in dead cells the dye is not excluded out. In this test, a cell suspension is mixed with dye and then microscopically examined for live and dead cells. The viable cells will have a clear cytoplasm whereas non-viable cells will have blue colour. A431 cells were treated in exponential growth phase with different doses of ST (30, 60 and $90 \mu \mathrm{M})$ for 48 and $72 \mathrm{~h}$. There was no significant difference between the control and ST treatments in total cell number (Figure 1B). We also did not observe any considerable difference in cell death of A431 cells after ST treatments (Figure 1E). In case of A549 cells, there was a significant decrease in total cell number by $8.2 \%(\mathrm{p} \leq 0.05)$ to $13.3 \%(\mathrm{p} \leq 0.05)$ in $48 \mathrm{~h}$ and $3.4 \%(\mathrm{p} \leq 0.05)$ to $13.7 \%$ $(\mathrm{p} \leq 0.0001)$ in $72 \mathrm{~h}$ (Figure $1 \mathrm{C})$. The increase in cell death of A549 cells was not significant except at $72 \mathrm{~h}$ of $90 \mu \mathrm{M}$ ST treatment (Figure 1F).

In case of MDA-MB-231 cells, there was a strong and significant cell growth inhibition which accounted for $31 \%(\mathrm{p} \leq 0.0001)$ to $63 \%(\mathrm{p} \leq 0.0001)$ in $48 \mathrm{~h}$ and $40 \%$ $(\mathrm{p} \leq 0.0001)$ to $50 \%(\mathrm{p} \leq 0.0001)$ in $72 \mathrm{~h}$ (Figure 1D). The increase in cell death was about $2 \%(\mathrm{p} \leq 0.05)$ to $15 \%$ $(\mathrm{p} \leq 0.0001)$ in $48 \mathrm{~h}$ and $1 \%(\mathrm{p} \leq 0.05)$ to $4 \%(\mathrm{p} \leq 0.0001)$ in $72 \mathrm{~h}$ of ST treatments as compared to their respective controls (Figure 1G). These results suggested better antiproliferative and cell death inducing effect of ST on MDA-MB-231 breast cancer cells as compared to skin carcinoma A431 and lung carcinoma A549 cells.

\section{Effect of $\beta$-Sitosterol on cell cycle progression of cancer cells}

Cell cycle analysis was done by quantitation of DNA content using propidium iodide fluorescent dye for each phases of the cell cycle by flow cytometry. The fluorescence intensity of the stained cells at certain wavelengths will therefore correlate with the amount of DNA they contain. A431 cells were treated with different doses of ST (30, 60 and $90 \mu \mathrm{M})$ for 48 and $72 \mathrm{~h}$. Cell cycle distribution analysis of A431 cells showed that, there were 3\% and $5 \%$ increases in $\mathrm{G} 2 / \mathrm{M}$ phase of cell population (Additional file 1: Figure S1A) in 48 and $72 \mathrm{~h}$ of ST treatments, respectively. A549 cells showed 4\% increase in S phase in $48 \mathrm{~h}$ of ST treatments (Additional file 1: Figure S1B). MDA-MB-231 cells showed 5\% and 3\% increases in G1 phase in $48 \mathrm{~h}$ and $72 \mathrm{~h}$ of ST treatments, respectively (Additional file 1: Figure S1C). Overall, only a moderate effect of ST was observed on cell cycle progression of cancer cells.

\section{Effect of $\beta$-Sitosterol on G0/G1 phase cell cycle protein levels in MDA-MB-231 cells}

Western blot analysis was done to study the molecular effect of ST on cell cycle regulatory molecules including cyclin-dependent kinase (CDK), Cyclin and CDKI (CDK inhibitor), which were involved in the G0/G1 arrest. Since we observed a moderate G0/G1 arrest in MDA-MB-231 cells, we analysed these cells after ST $(60-90 \mu \mathrm{M})$ of $48 \mathrm{~h}$ that showed a dose-dependent decrease in CDK4 and cyclin D1 protein levels with stronger effect at higher concentration (Figure 2A). We also examined the effect of ST treatment on negative regulator of cell cycle, i.e. (CDKI) such as p21/Cip1 and p27/Kip1, that controls the activity of CDK through various phases of cell cycle, including G0/G1. We observed an increase in p21/Cip1 and p27/Kip1 protein levels which were relatively higher at $90 \mu \mathrm{M}$ concentration of ST and may explain the effect for G0/G1 arrest compared to control (Figure 2A). These results suggest that ST induced G0/G1 arrest in MDA-MB-231 cells could be mediated via modulation of CDK-cyclin-CDKI protein levels.

\section{Effect of $\beta$-Sitosterol on Erk1/2 and Akt activation in MDA-MB-231 cells}

After $48 \mathrm{~h}$ of ST treatment we observed a dosedependent increase in Erk1/2 phosphorylation without any change in its total protein level (Figure 2B). However, we did not observe any considerable change in protein levels of $\mathrm{p}$-Akt and total Akt as compared to control (Figure 2B). These results suggest that ST may preferentially activate Erk1/2 signaling for its growth inhibitory and cell death inducing effects on MDA-MB231 cells.

\section{Effect of $\beta$-Sitosterol on apoptotic cell death in MDA-MB- 231 cells}

Apoptosis is a cell death process characterized by morphological and biochemical features occurring at different 

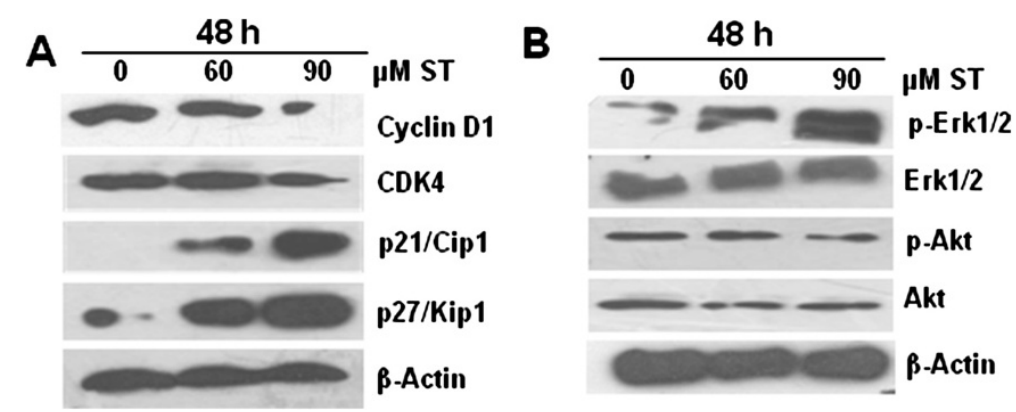

Figure 2 Effect of $\beta$-sitosterol (ST) on G0/G1 phase cell cycle regulators and mitogenic and survival signaling in breast cancer cells. MDAMB-231 cells were treated with either DMSO control or various doses of $\beta$-Sitosterol (60 and $90 \mu \mathrm{M})$ for $48 \mathrm{~h}$. At the end of these treatments, cell lysate was prepared and western blot analysis was performed. Membranes were probed with (A) anti-cyclin D1, CDK-4, p21/Cip1, p27/Kip1, and (B) anti-pErk1/2, Erk1/2, p-Akt and Akt antibodies followed by peroxidase-conjugated appropriate secondary antibodies, and visualized by ECL detection system. Membranes were striped and re-probed with anti- $\beta$ actin for loading control.

stages. The cells undergoing apoptosis translocate phosphatidyl serine to the outer layer of the membrane. This occurs in the early phases of apoptotic cell death during which the cell membrane remains intact [19]. The morphology of MDA-MB-231 cells as compared to A431 and A549 cells after $48 \mathrm{~h}$ of ST treatment suggests that cells may undergo apoptosis (Figure 3). To investigate this possibility MDA-MB-231 cells were treated with 60 and $90 \mu \mathrm{M}$ of ST for 48 and $72 \mathrm{~h}$, and stained with FITCannexin $\mathrm{V}$ and analyzed by flow cytometry. There was up to 2 -fold $(\mathrm{p} \leq 0.05)$ increase in apoptotic cell population following ST treatment (data not shown).

Bcl-2 is anti-apoptotic protein whereas Bax is a proapoptotic protein, and ration of both is known to determine the apoptotic response of the cell. To investigate the anti-apoptotic and pro-apoptotic gene expression, western blotting was performed against $\mathrm{Bcl}-2$ and $\mathrm{Bax}$ proteins. A concentration-dependent decrease was observed in Bcl-2 protein level whereas Bax showed a moderate concentration-dependent increase after $48 \mathrm{~h}$ of ST treatment (Figure 4A). There was a 2-4 fold increase in Bax/Bcl-2 ratio (Figure $4 \mathrm{~B}$ ), suggesting that induction of apoptosis involving mitochondria could be one of the mechanisms of cell death induced by ST.

\section{Effect of $\beta$-Sitosterol mitochondrial membrane potential in MDA-MB-231 cells}

The loss of mitochondrial membrane potential is a hallmark for apoptosis [20]. JC-1(5,5",6,6"- tetrachloro-1,1",3,3"tetraethylbenzimidazolylcarbocyanineiodide) is used mostly for detecting mitochondrial depolarization occurring in the early stages of apoptosis. It exhibits potentialdependent accumulation in mitochondria, indicated by a fluorescence emission shift from green to red. In nonapoptotic cells, JC-1 exists as dimer and accumulates as aggregates in the mitochondria which stains red. Whereas, in apoptotic and necrotic cells, JC-1 exists in monomeric form in cytosol and stains the cytosol green. Changes in the mitochondrial membrane potential $(\Delta \Psi)$ were analyzed using JC-1 dye.

Cells were similarly seeded and treated as in apoptosis assay. After treatment cells were harvested and processed for JC-1 staining and subjected to flow cytometry. Red to green shift suggests the shift from JC-1 dimer to JC-1 monomer (Figure 5A). Results show that there was a significant increase in monomer/dimer ratio which accounted for 4.5 fold increase $(\mathrm{p} \leq 0.05)$ at $60 \mu \mathrm{M} \mathrm{ST}$, and 5 -fold increase $(\mathrm{p} \leq 0.001)$ at $90 \mu \mathrm{M} \mathrm{ST}$ after $24 \mathrm{~h}$ of treatment (Figure $5 \mathrm{~B}$ ). This result suggests that $\mathrm{ST}$ causes depolarization of mitochondrial membrane potential which could be linked with the induction of apoptosis in breast cancer cells.

\section{Discussion}

Chemoprevention is a promising strategy which involves intervention by natural and synthetic agents at early stages in the disease process or in high risk individuals to reduce the development of cancer [21]. This strategy is promising for reducing cancer incidence both in well-defined high-risk groups of people as well as in the general population. There is an urgent need to explore potent, non-toxic and less expensive chemopreventive agents that inhibit cancer growth and progression.

Our present investigation of ST against human skin epidermoid carcinoma cell line A431, human lung epithelial carcinoma cell line A549 and human breast adenocarcinoma cell line MDA-MB-231 is an effort to find its anticancer efficacy in different epithelial cancers. The results of cell counting data clearly show that ST does not have any significant effect on cell growth, cell death and cell cycle progression in A431 cells. However, a minor but considerable effect was observed only for cell growth inhibition without any effect on cell death or cell cycle progression in A549 cells. In case of MDAMB-231 cells, ST showed a significant growth inhibition, cell death and cell cycle arrest. These observations 

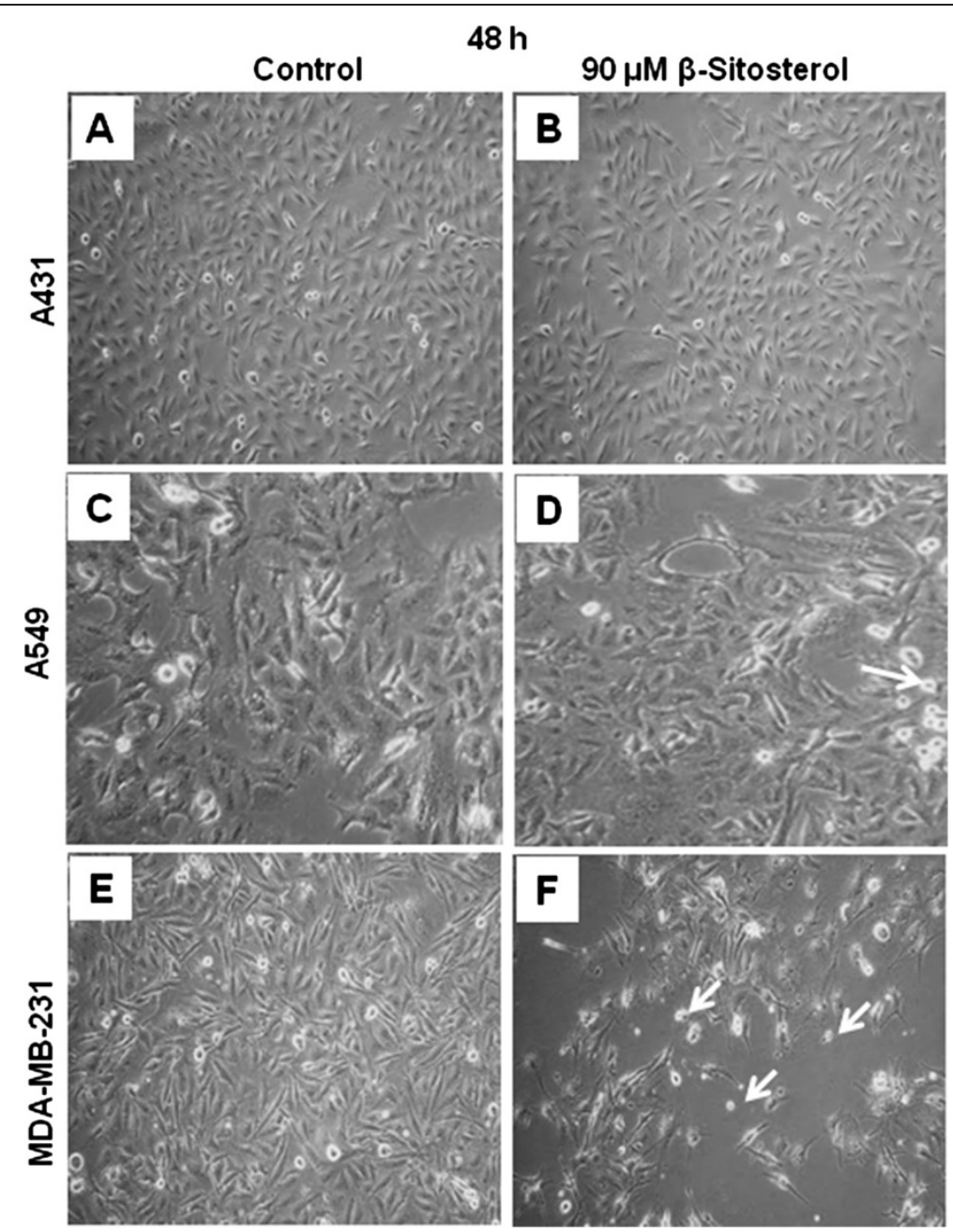

Figure 3 Effect of $\beta$-sitosterol (ST) on cell morphology of human skin epidermoid carcinoma, human lung epithelial carcinoma and human breast carcinoma cells. (A \& B) A431, (C \& D) A549, and (E \& F) MDA-MB-231 cells were treated with 90 HM ST for 48 h. A, C and E represents untreated cells whereas B, D and F represents the cells treated with ST. Arrows indicate the shrinkage of cell with condensed nuclei which may apoptotic in nature.
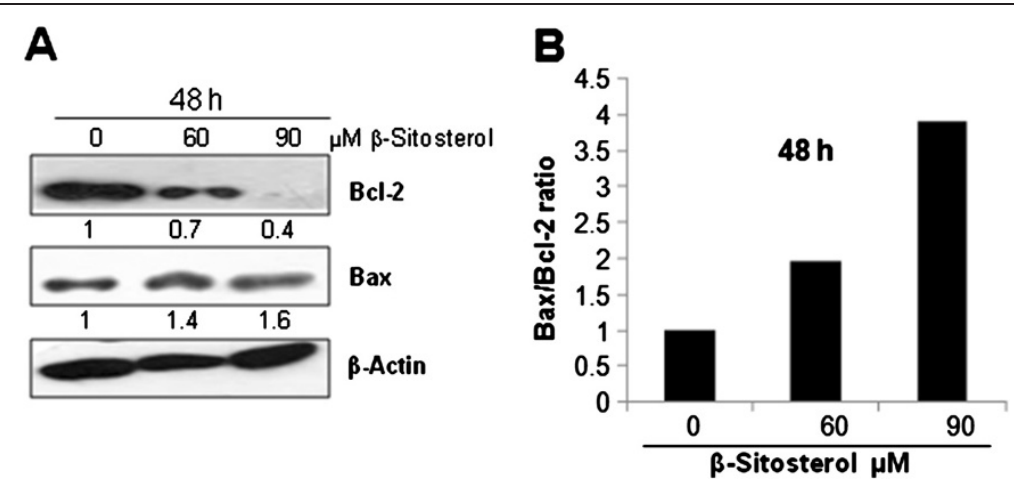

Figure 4 Effect of $\beta$-sitosterol (ST) on apoptosis and Bax/Bcl-2 ratio in breast carcinoma cells. MDA-MB-231 cells were treated with DMSO (control) or 60 and $90 \mu \mathrm{M} \mathrm{ST}$ for 48 h. (A) Western blot analyses were performed to examine the expression level of Bax and Bcl-2 proteins. Membranes were probed with anti-Bax and Bcl-2 antibodies followed by peroxidase-conjugated appropriate secondary antibodies, and visualized by ECL detection system. Membrane was striped and re-probed with anti- $\beta$ actin for loading control. Densitometric value of bands are shown below each band as fold change from that of control and corrected with loading control (B) Represents the ratio of Bax/Bcl-2 protein expression levels. 


\section{A JC-1 flow cytometry analysis}
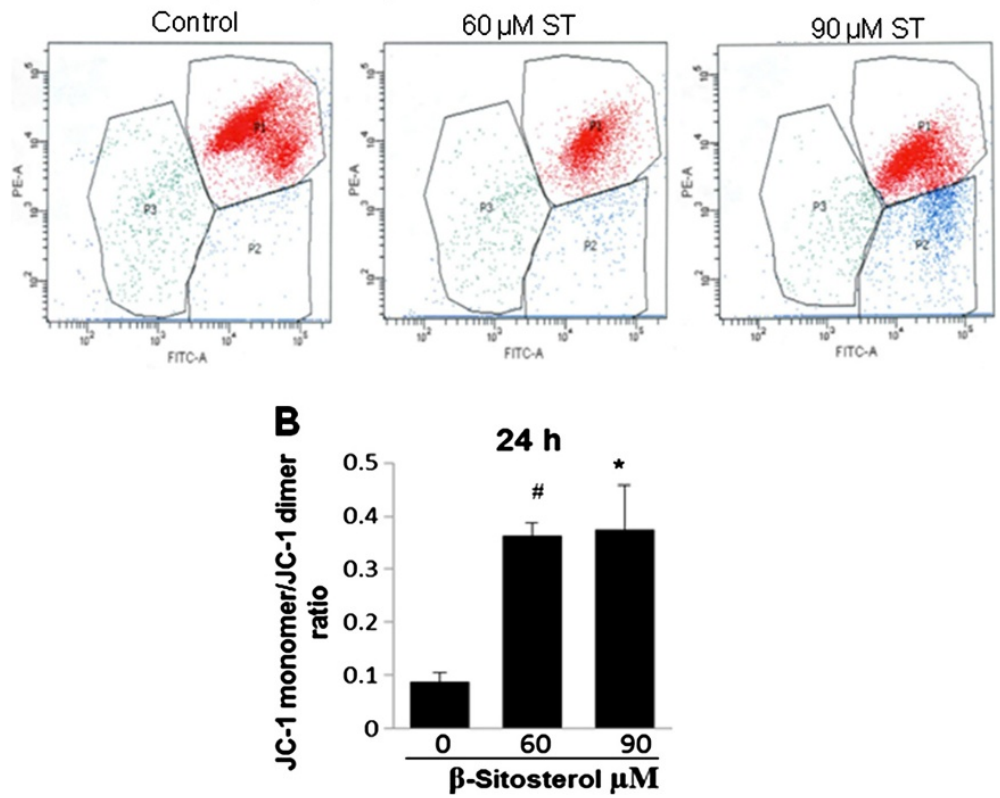

Figure 5 Effect of $\beta$-sitosterol (ST) on mitochondrial membrane potential in breast carcinoma cells. MDA-MB-231 cells were treated with DMSO (control) or 60 and $90 \mu \mathrm{M}$ ST for $24 \mathrm{~h}$. (A) Mitochondrial membrane potential was measured by JC-1 staining and analyzed by flow cytometry as described in Methods. (B) The quantitative data is presented as means of $590 \mathrm{~nm} / 520 \mathrm{~nm}$ (P2/P1) emission spectrum. The data shown are mean \pm S.E. of triplicate samples for each treatment. \#, $p<0.05 ;{ }^{*}, p<0.001$ compared with control.

suggest that ST has differential efficacy for skin, lung and breast cancer cells which is in order of A431 < A549 $<<$ MDA-MB-231.

The cancer chemopreventive strategies include the targeting of limitless replication potential and deregulated cell cycle progression in cancer cells [22]. Cell cycle progression is mediated by the activity of cyclin-dependent kinases (CDK) in complex with regulatory subunit cyclins [23]. A frequent target in carcinogenesis is the deregulation of $\mathrm{G} 1$ to $\mathrm{S}$ phase progression of the cell cycle [24]. Cyclin D1 is a key regulatory protein at G1/S checkpoint of the cell cycle that forms complexes with CDK4 or CDK6. It is considered as an oncogene, and overexpressed in many cancers, including prostate, breast, esophagus, lung, head and neck and colon [25,26]. It acts as a growth sensor and provides a link between mitogenic stimuli and the cell cycle. CDK4 is a key factor in promoting the initiation and development of tumors [27], and amplified and over expressed in a number of human tumors including the gliomas, sarcomas, breast tumors and colorectal carcinomas [28]. Since we observed considerable G1 phase arrest in MDA-MB-231 cells, we also did analysis for the cyclin D1 and CDK4 protein levels which were decreased after ST treatment. This suggests that downregulation of cyclin D1 and CDK4 may be associated with ST-induced G1 phase arrest in breast carcinoma cells.

Cyclin-dependent kinase inhibitors (CDKI) are tumor suppressor proteins that bind to active CDK-cyclin complexes and inhibit their kinase activities [29]. p21/ Cip1 is a universal CDKI and plays a critical role in the cellular response for cell cycle arrest [30]. p27/Kip1 is another important member of CDKI which connects the anti- proliferative signals for cell cycle arrest [31]. Lower level of p27/Kip1 protein is known as a prognostic marker for many cancers [32].

Our study showed that ST increases p21/Cip1 and p27/Kip1 protein levels in MDA-MB-231 cells, and thus it can also take part in inhibiting the kinase activity of CDK. Together, ST-induced G1 arrest could be mediated via down-regulation of CDK 4 and cyclin D1, and up regulation of p21/Cip1 and p27/Kip1 in MDA-MB-231 cells. Furthermore, the changes observed at molecular level suggest that these CDKI might be having alternative mechanism/s such as apoptosis, other than their cell cycle effect, however, further studies are needed to explore such assumptions.

Apoptosis is suggested as one of the major mechanisms for the targeted therapy of various cancers including breast cancer [33]. Most of the presently available cytotoxic anticancer drugs mediate their effect via apoptosis in cancer cells [34]. Changes in negatively charged phosphatidyl serine (PS) asymmetry in cell membrane is analyzed by its binding with annexin $\mathrm{V}$ conjugated with FITC by flow cytometry. Annexin V analysis suggests that ST caused cell death is mainly because of apoptosis induction in MDA-MB-231 cells. The longer exposure 
of lower dose $(60 \mathrm{uM})$ of ST showed time-dependent effect for apoptosis; however, the higher dose $(90 \mathrm{uM})$ achieved its maximum effect at $48 \mathrm{~h}$ after the treatment. Next, we explored the molecular alterations associated with apoptosis.

The Bcl-2 family includes both anti-apoptotic (e.g., Bcl-2 itself) and pro-apoptotic (e.g., Bax) proteins. Their expression levels, interaction, ratio, and translocation of different members determine the overall pro-apoptotic or anti-apoptotic fate of the cell [35]. The increased expression of Bax is often associated with the increased apoptosis whereas the increased expression of Bcl-2 is associated with the inhibition of apoptosis and cell survival mechanisms [36]. Western blotting analysis showed a decrease in expression level of Bcl-2 and an increase in expression level of Bax. Furthermore, there was a strong increase in Bax to Bcl-2 ratio, which is known to favor apoptosis [36] suggesting that ST caused increase in $\mathrm{Bax} / \mathrm{Bcl}-2$ ratio may play a significant role in induction of apoptosis in MDA-MB-231 cells. To further investigate the molecular changes associated with apoptosis induction by ST in MDA-MB-231 cells, mitochondrial membrane potential was measured. ST caused the depolarization of mitochondrial membrane potential which is associated with the induction of an early apoptotic event leading to mitochondrial apoptosis in cells.

\section{Conclusions}

The current study shows that $\beta$-Sitosterol (ST), a dietary phytosterol has stronger anticancer activity against breast cancer cells compared to lung and skin cancer cells which may be attributed to the differential expression of genes including hormones, receptors and tissue specific proteins (Additional file 2: Figure S2). Along with anti-proliferative and growth inhibitory effect, ST induced G0/G1 cell cycle arrest via modulation of cell cycle regulators CDK4, cyclin D1, p21/Cip1and p27/ Kip1 breast cancer cells. Further ST caused cell death involves the induction of apoptosis in breast cancer cells via mitochondrial membrane depolarization and increase in Bax/Bcl-2 ratio. This study provides valuable insight into the chemopreventive efficacy and associated molecular alterations of ST in breast cancer cells. However, further studies are needed to understand and assess the potential clinical utility of ST as a chemopreventive agent against breast cancer.

\section{Additional files}

Additional file 1: Figure S1. Effect of $\beta$-sitosterol (ST) on cell cycle progression in cancer cells. (A) A431, (B) A549 and (C) MDA-MB-231 cells were treated with either DMSO control or various doses of $\beta$-Sitosterol (60 and $90 \mu \mathrm{M}$ ) for 48 and $72 \mathrm{~h}$. Cell cycle analysis was performed at the end of each treatment as detailed in Methods.
Additional file 2: Figure S1. Differential effects of $\beta$-sitosterol on human cancer cell lines. $\beta$-sitosterol up-regulates CDKIs, p21 and p27 and down-regulates cyclin D1 and CDK4 to induce G1 arrest in breast adenocarcinoma MDA- MB-231 cells. On the other hand, it causes an increase in $\mathrm{Bax} / \mathrm{BCl}-2$ ratio and mitochondrial membrane depolarization to induce apoptosis in breast cancer cells.

\section{Abbreviations}

ST: $\beta$-sitosterol; CDK: Cyclin-dependent kinase; CDKI: Cyclin-dependent kinase inhibitor; FACS: Fluorescence-activated cell sorting.

\section{Competing interests}

The authors declare that they have no competing interests.

\section{Authors' contributions}

SSV has done the experiment and written the manuscript; RKK has contributed in developing of hypothesis and designing of experiment; RPS has developed hypothesis, designed experiments, written the manuscript and overall supervised the study. All authors read and approved the final manuscript.

\section{Acknowledgements}

The work was supported by the funds from CUG, Gandhinagar and UGCResource Networking, JNU, India. SSV is supported by UGC non-NET fellowship from CUG, Gandhinagar, India.

Received: 14 June 2013 Accepted: 24 September 2013

Published: 25 October 2013

\section{References}

1. Ferlay J, Shin H, Bray F, Forman D, Mathers C, Parkin D: Estimates of worldwide burden of cancer in 2008. Int J Cancer 2010, 127:2893-2917.

2. American Cancer Society: Cancer Facts and Figures: 2010. Atlanta: American Cancer Society; 2010:1-62.

3. Anne S, Tsao M, Edward S, Kim M, Waun Ki Hong M: Chemoprevention of cancer. Am Cancer J Clin 2004, 54:150-180.

4. Nishino H, Tokuda H, Satomi Y, Masuda M, Onozuka M, Yamaguchi S, Takayasu J: Cancer chemoprevention by phytochemicals and their related compounds. Asian Pacific J Cancer 2000, 1:49-55.

5. Dragsted L, Strube M, Larsen J: Cancer-protective factors in fruits and vegetables: biochemical and biological background. Pharmacol Toxicol 1993, 72:116-135.

6. Demirkol O, Adams C, Ercal N: Biologically important thiols in various vegetables and fruits. J Agric Food Chem 2004, 52:8151-8154.

7. Chandra S, Sah K, Bagewadi A, Keluskar V, Shetty A: Additive and synergistic effect of phytochemicals in prevention of oral cancer. Eur J Gen Dent 2012, 1:142-147.

8. Valsta L, Lemström A, Ovaskainen M, Lampi A, Toivo J, Korhonen T, Piironen $\checkmark$ : Estimation of plant sterol and cholesterol intake in Finland: quality of new values and their effect on intake. Br J Nutr 2007, 92:671-678.

9. Trautwein E, Lin Y, Mel S, Molhuizen H, Ntanios F: Proposed mechanisms of cholesterol-lowering action of plant sterols. Eur J Lipid Sci Technol 2003, 105:171-185.

10. Bouic P, Lamprecht J: Plant Sterols and Sterolins: A review of their Immune-modulating properties sterols \& sterolins. Altern Med Rev 1999, 4:170-177.

11. Awad A, Chinnam M, Fink C, Bradford P: Beta-Sitosterol activates Fas signaling in human breast cancer cells. Phytomedicine 2007, 14:747-754.

12. Awad A, Burr A, Fink C: Effect of resveratrol and beta-sitosterol in combination on reactive oxygen species and prostaglandin release by PC-3 cells. Prostaglandins Leukot Essent Fat Acids 2005, 72:219-226.

13. Von Holtz R, Fink C, Awad A: Beta-Sitosterol activates the sphingomyelin cycle and induces apoptosis in LNCaP human prostate cancer cells. Nutr Cancer 1998, 32:8-12.

14. Bhat TA, Nambiar D, Pal A, Agarwal R, Singh RP: Fisetin inhibits various attributes of angiogenesis in vitro and in vivo-implications for angioprevention. Carcinog 2012, 33:385-393.

15. Yim D, Singh RP, Agarwal C, Lee S, Chi H: A novel anticancer agent decursin, induces $\mathrm{G} 1$ arrest and apoptosis in human prostate carcinoma cells. Cancer Res 2005, 65:1035-1044. 
16. Luo KW, Sun JG, Chan JY, Yang L, Wu SH, et al: Anticancer effects of imperatorin isolated from Angelica dahurica: induction of apoptosis in HepG2 cells through both death-receptor- and mitochondria-mediated pathways. Chemother 2011, 57:449-459.

17. Agarwal C, Singh RP, Dhanalakshmi S, Tyagi AK, Tecklenburg M, Sclafani RA, Agarwal R: Silibinin upregulates the expression of cyclin-dependent kinase inhibitors and causes cell cycle arrest and apoptosis in human colon carcinoma HT-29 cells. Oncogene 2003, 22:8271-8282.

18. Varghese L, Agarwal C, Tyagi A, Singh RP, Agarwal R: Silibinin efficacy against human hepatocellular carcinoma. Clin Cancer Res 2005, 11:8441-8448.

19. Sheu MJ, Huang GJ, Wu CH, Chen JS, Chang HY, Chang SJ, Chang JG: Ethanol extract of Dunaliella salina induces cell cycle arrest and apoptosis in A549 human non-small cell lung cancer cells. In Vivo 2004, 212:369-378.

20. Singh T, Sharma SD, Katiyar SK: Grape proanthocyanidins induce apoptosis by loss of mitochondrial membrane potential of human nonsmall cell lung cancer cells in vitro and in vivo. PLoS One 2011, 6:e27444

21. Kakizoe T: Chemoprevention of cancer - focusing on clinical trials. Japanese J Clin Oncol 2003, 33:421-442.

22. Deep G, Singh RP, Agarwal C, Kroll DJ, Agarwal R: Silymarin and silibinin cause G1 and G2-M cell cycle arrest via distinct circuitries in human prostate cancer PC3 cells: a comparison of flavanone silibinin with flavanolignan mixture silymarin. Oncogene 2006, 25:1053-1069.

23. Kastan MB, Canman CE, Leonard CJ: P53, cell cycle control and apoptosis: implications for cancer. Cancer Metastasis Rev 1995, 14:3-15.

24. Blagosklonny MV, Pardee AB: The restriction point of the cell cycle. Cell Cycle 2002, 1:103-110.

25. Bartkova J, Lukas J, Strauss M, Bartek J: Cyclin D1 oncoprotein aberrantly accumulates in malignancies of diverse histogenesis. Oncogene 1995, 10:775-778.

26. Dong Y, Sui L, Sugimoto K, Tai Y, Tokuda M: Cyclin D1-CDK4 complex, a possible critical factor for cell proliferation and prognosis in laryngeal squamous cell carcinomas. Int J Cancer 2001, 95:209-215.

27. Wu A, Wu B, Guo J, Luo W, Wu D, Yang H, Zhen Y, et al: Elevated expression of CDK4 in lung cancer. J Transl Med 2011, 9:1-9.

28. Lantsov D, Meirmanov S, Nakashima M, Kondo H, Saenko V, Naruke Y, Namba H: Cyclin D1 overexpression in thyroid papillary microcarcinoma: its association with tumour size and aberrant beta-catenin expression. Histopathol 2005, 47:248-256.

29. Singh RP, Agarwal R: Flavonoid antioxidant silymarin and skin cancer. Antioxid Redox Signal 2002, 4:655-663.

30. Fang L, Igarashi M, Leung J, Sugrue MM, Lee SW, Aaronson SA: p21Waf1/ Cip1/Sdi1 induces permanent growth arrest with markers of replicative senescence in human tumor cells lacking functional p53. Oncogene 1999, 18:2789-2797

31. Polyak K, Lee MH, Erdjument BH, Koff A, Roberts JM, Tempst P, Massagué J: Cloning of p27Kip1, a cyclin-dependent kinase inhibitor and a potential mediator of extracellular antimitogenic signals. Cell 1994, 78:59-66.

32. Lloyd RV, Erickson LA, Jin L, Kulig E, Qian X, Cheville JC, Scheithauer BW: p27/kip1: A multifunctional cyclin-dependent kinase inhibitor with prognostic significance in human cancers. Am J Pathol 1999, 154:313-323.

33. Osborne C, Wilson P, Tripathy D: Oncogenes and tumor suppressor genes in breast cancer: potential diagnostic and therapeutic applications. Oncologist 2004, 9:361-377.

34. Singh RP, Agarwal C, Agarwal R: Inositol hexaphosphate inhibits growth, and induces $\mathrm{G} 1$ arrest and apoptotic death of prostate carcinoma DU145 cells: modulation of CDKI-CDK-cyclin and pRb-related protein-E2F complexes. Carcinog 2003, 24:555-563.

35. Cory S, Huang DCS, Adams JM: The Bcl-2 family: roles in cell survival and oncogenesis. Oncogene 2003, 22:8590-8607.

36. Katiyar SK, Roy AM, Baliga MS: Silymarin induces apoptosis primarily through a p53-dependent pathway involving Bcl-2/Bax, cytochrome release, and caspase activation. Mol Cancer Ther 2005, 4:207-216.

doi:10.1186/1472-6882-13-280

Cite this article as: Vundru et al.: $\beta$-sitosterol induces G1 arrest and causes depolarization of mitochondrial membrane potential in breast carcinoma MDA-MB-231 cells. BMC Complementary and Alternative Medicine 2013 13:280

\section{Submit your next manuscript to BioMed Central and take full advantage of:}

- Convenient online submission

- Thorough peer review

- No space constraints or color figure charges

- Immediate publication on acceptance

- Inclusion in PubMed, CAS, Scopus and Google Scholar

- Research which is freely available for redistribution 